\title{
Complications in IDDM are caused by elevated blood glucose level: The Stockholm Diabetes Intervention Study (SDIS) at 10-year follow up
}

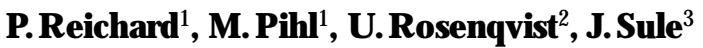 \\ ${ }^{1} \mathrm{D}$ epartment of Internal M edicine, Södersjukhuset, Stockholm, Sweden \\ ${ }^{2} \mathrm{D}$ epartment of Social M edicine, U ppsala U niversity, U ppsala, Sweden \\ 3 in private practice
}

Summary Blood glucose values close to normal reduce the microvascular complications of insulin-dependent diabetes mellitus. The Stockholm study of this effect continued after the initial 7.5-year period in order to see what happened when intensively treated patients were left to control their own treatment while treatment was intensified in the control group. Forty-three patients with insulin-dependent diabetes randomised to intensified conventional treatment (ICT) and 48 patients randomised to standard treatment (ST) were followed-up for 10 years. Vascular complications, treatment side-effects and well-being were studied. Risk factors for complications were sought. $\mathrm{HbA}_{1 \mathrm{c}}$ (normal range 3.9-5.7\%) was reduced from $9.5 \pm 1.4 \%$ (mean \pm SD) in the ICT group and $9.4 \pm 1.2 \%$ in the ST group to a mean (during 10 years) of $7.2 \pm 0.6 \%$ and $8.3 \pm 1.0 \%$, respectively $(p<0.001)$. Serious retinopathy $(63$ vs $33 \%$, $p=0.003$ ), nephropathy ( 26 vs $7 \%, p=0.012$ ) and symptoms of neuropathy ( 32 vs $14 \%, p=0.041$ ) were more common in the ST group after 10 years. $\mathrm{HbA}_{1 \mathrm{c}}$ and age were the only risk factors for complications. Self-reported well-being increased to a greater degree and severe hypoglycaemia was more common in the ICT group. Cognitive function after 10 years was similar in both treatment groups, and was not related to the number of severe hypoglycaemic episodes. Intensified insulin treatment leads to reduced long-term complications and increased well-being without causing undue side-effects. [D iabetologia (1996) 39: 1483-1488]

Keywords Insulin-dependent diabetes mellitus, intensified treatment, complications, well-being, side-effects.
Intensified insulin treatment and lower, albeit still supraphysiological, blood glucose levels retard the long-term microvascular complications of insulin-dependent diabetes mellitus [1, 2].

The Diabetes Control and Complications Trial (DCCT) [1] was ended after a mean of 6.5 years'

R eceived: 1 A pril 1996 and in revised form: 12 July 1996

Corresponding author: D r. P. R eichard, D epartment of Internal M edicine, Södersjukhuset, S-11883 Stockholm, Sweden A bbreviations: DCCT, Diabetes Control and Complications Trial; SDIS, Stockholm D iabetes I ntervention Study; ICT, intensified conventional treatment; ST, standard treatment; B M I, body mass index; E TD R S, E arly Treatment D iabetic R etinopathy Study; ACE, angiotensin converting enzyme; OR, odds ratio. study. The Stockholm Diabetes Intervention Study (SD IS) [2] has continued for 10 years, although the protocol changed twice (after 3 years [3] and after 7.5 years), in order to achieve lower blood glucose levels in the control group, and the second time also in order to let the intensively treated patients return to routine diabetes care. The aim of the present report is to clarify whether the results reported earlier remain when the treatment groups have returned to routine care and to see if there are independent risk factors for diabetic late complications.

\section{Subjects and methods}

The study protocol was accepted by the ethics committee at $K$ arolinska Institute, Stockholm, and the patients gave their informed consent before they entered the study. 
We selected and randomised 102 patients as described [2, 4]. A fter 10 years, 7 patients had died, and 4 were partly lost to follow-up. Of the remaining patients, 43 had been randomised to intensified conventional treatment (ICT) while 48 received standard treatment (ST). The mean age at entry into the study was $31 \pm 7$ years (mean \pm SD) and the mean diabetes duration was $17 \pm 6$ years, not significantly different between the groups. Of the patients consecutively found to be eligible $92 \%$ agreed to participate [4].

The treatment programmes have been described, and consisted primarily of education and continuous tutoring [5]. A fter 7.5 years' study the ICT patients had regular visits every 4 months. $M$ any of the ST patients had frequent contact with the physician after the 7.5-year period, and were then given advice on how to further improve their treatment. The goal was to reduce the $\mathrm{HbA}_{1 \mathrm{c}}$ to $7 \%$, and the patients were informed that the study so far had shown that this was the level of $\mathrm{HbA}_{1 c}$ needed in order to halt the long-term complications. The intensification of treatment in the ST group thus consisted of information, education, close office contacts, home blood glucose tests and for most of the patients three or more injections daily. Two patients in the ST group but none in the ICT group, also began to use subcutaneous insulin infusion treatment with a pump.

Each patient who had a blood pressure above 140/ $90 \mathrm{~mm} \mathrm{H}$ g received anti-hypertensive medication [2].

Smoking habits were assessed with interviews, and the patients were divided into smokers and non-smokers.

Glycated haemoglobin, $\mathrm{HbA}_{1 \mathrm{c}}$ (normal range 3.9-5.7\%), was measured as described previously $[2,4]$. The value at baseline was compared with the mean of values obtained every 4 months.

A II patients were followed up with regard to mortality, ketoacidosis, body mass index $\left(\mathrm{BM} \mathrm{I}, \mathrm{kg} / \mathrm{m}^{2}\right)$ and severe hypoglycaemia (requiring help from someone else) $[2,6-7]$. Subjective well-being and perceived ability to control the diabetes were analysed graphically [5]. The effects of severe hypoglycaemia on cognitive function were followed with a battery of computerised tests [6-8]. The most sensitive tests were used for group comparison.

Severe retinopathy [2] (any proliferative retinopathy or macular oedema requiring photocoagulation) was studied with fundus examinations through dilated pupils 126 (94-145) months (median, range) after the baseline examination, not different between the groups. B est corrected visual acuity was assessed with $M$ onoyer-G ranström charts, and a loss of at least two lines in one eye was defined as deterioration [2]. A fter 120 months, fundus photographs were obtained from six fields of the retina [9]. These fields were graded according to a modified ETDR S (E arly Treatment D iabetic R etinopathy Study)system [10] with regard to red dots, as described previously [4, 10]. The mean score for the six fields is given. The ophthalmologists participating were blinded as to individual treatment groups.

A lbuminuria, neuropathy and glomerular filtration rate were measured as described [2-4, 11, 12]. N ephropathy was defined as a urinary albumin excretion rate greater than $200 \mu \mathrm{g} /$ min. The glomerular filtration rate had a lower normal limit of $77 \mathrm{ml} / \mathrm{min}$. Blood pressure was measured in the supine position as described [2].

N europathy was studied only in the legs, in order to exclude symptoms from median nerve compression. Symptoms were: subjective sensory loss, paraesthesia and/or lancinating pain without other explanation. Pin prick sensitivity was studied with a fine needle on the medial dorsum of the dominant foot and on the great toe. Nerve conduction velocities were measured [11]. Neuropathy was defined as subjective symptoms
Table 1. $\mathrm{HbA}_{1 \mathrm{c}}$ in the intensified conventional treatment group and the standard treatment group

\begin{tabular}{llcc}
\hline & $\begin{array}{l}\text { Intensified } \\
\text { conventional } \\
\text { treatment }\end{array}$ & $\begin{array}{l}\text { Standard } \\
\text { treatment }\end{array}$ & p-values \\
\hline Baseline & $9.5 \pm 1.4$ & $9.4 \pm 1.2$ & $\mathrm{NS}, 0.0932$ \\
6-90 months & $7.1 \pm 0.6$ & $8.4 \pm 1.0$ & $<0.001$ \\
94-120 months & $7.3 \pm 0.9$ & $8.1 \pm 1.2$ & 0.001 \\
6-120 months & $7.2 \pm 0.6$ & $8.3 \pm 1.0$ & $<0.001$ \\
\hline
\end{tabular}

Values are \% (mean \pm SD)

Figures are given only for the patients who could be followed for 10 years ( 43 ICT and $48 \mathrm{ST}$ )

combined with at least one reduced nerve conduction velocity $(<41 \mathrm{~m} / \mathrm{s})$.

In multivariate analyses serious retinopathy, overt nephropathy and neuropathy were analysed against a number of potential risk factors for complications: duration of diabetes, diastolic blood pressure at baseline, smoking habits at time of entry and after 10 years, $\mathrm{HbA}_{1 \mathrm{c}}$ at baseline, age, age at diagnosis of diabetes, BMI and insulin dose at entry to and after 10 years of the study. These were studied in univariate analyses, in a multivariate analysis together without $\mathrm{HbA}_{10}$ and then all the significant variables together with mean $\mathrm{HbA}$ ic during the study.

\section{Statistical analysis}

When not otherwise stated results are presented as mean \pm SD or with $95 \%$ confidence intervals. Comparisons between and within groups were made with Student's t-test, analysis of variance, Mann-Whitney's U -test, Wilcoxon's sign rank test, or the chi square test. A II comparisons were two-tailed. Correlations were analysed with Spearman's method. Proportions were analysed [13] and serious retinopathy was studied with a life table analysis [14]. Multivariate analyses were performed with multiple linear regression for continuous or logistic regression [15] presenting the odds ratio (OR) (95\% confidence interval) for dichotomous dependent variables when the independent variable changed by one unit (e.g. a change of $\mathrm{HbA}$ from 7 to $8 \%$ ). E ffects of the intensified programme if generally implemented were studied with confidence interval analysis [13].

\section{Results}

A fter 10 years, $89 \%$ of the ICT patients and $71 \%$ of the ST patients were treated with at least three daily insulin injections. Four patients in the ST group and one patient in the ICT group experienced an episode of ketoacidosis. Four patients in the ICT group and three patients in the ST group died [8].

The number of smokers (initially $52 \%$ of the ICT patients and $50 \%$ of the ST patients, $p=0.824$ ) decreased by $40 \%$ in the ICT group and by $23 \%$ in the ST group $(p=0.195)$. No patient started smoking during the study.

$\mathrm{M}$ ean $\mathrm{HbA}$ 1c during the study was significantly lower in the ICT group (Table 1), and did not rise very much when the patients in the ICT group were 
Table 2. Serious retinopathy, visual deterioration and nephropathy during 10 years in the treatment groups

\begin{tabular}{|c|c|c|c|}
\hline & $\begin{array}{l}\text { Intensified } \\
\text { conventional } \\
\text { treatment }\end{array}$ & $\begin{array}{l}\text { Standard } \\
\text { treatment }\end{array}$ & $\mathrm{p}$-values \\
\hline $\begin{array}{l}\text { Serious retinopathy: } \\
\text { baseline } \\
10 \text { years }\end{array}$ & $\begin{array}{r}0 \\
33\end{array}$ & $\begin{array}{r}0 \\
63\end{array}$ & 0.003 \\
\hline $\begin{array}{l}\text { Visual deterioration during } \\
10 \text { years }\end{array}$ & 18 & 37 & 0.04 \\
\hline $\begin{array}{l}\text { Nephropathy: } \\
\text { baseline } \\
10 \text { years }\end{array}$ & $\begin{array}{l}5 \\
7\end{array}$ & $\begin{array}{r}7 \\
26\end{array}$ & 0.012 \\
\hline
\end{tabular}

Values are $\%$ of patients

Table 3. G lomerular filtration rate $\left({ }^{51} \mathrm{CrEDTA}\right.$ clearance, $\mathrm{ml} /$ $\min$ ) and blood pressure in the treatment groups at baseline and after 10 years

\begin{tabular}{|c|c|c|c|}
\hline & $\begin{array}{l}\text { Intensified } \\
\text { conventional } \\
\text { treatment }\end{array}$ & $\begin{array}{l}\text { Standard } \\
\text { treatment }\end{array}$ & $p$-values \\
\hline $\begin{array}{c}\text { G lomerular } \\
\text { baseline } \\
10 \text { years }\end{array}$ & $\begin{array}{l}123 \pm 19 \\
110 \pm 18\end{array}$ & $\begin{array}{l}127 \pm 22 \\
109 \pm 25\end{array}$ & $\begin{array}{l}0.332 \\
0.927\end{array}$ \\
\hline $\begin{array}{l}\text { Systolic bloc } \\
\text { baseline } \\
10 \text { years }\end{array}$ & $\begin{array}{l}\mathrm{mmH} \mathrm{g}): \\
129.3 \pm 13.5 \\
124.9 \pm 15.4^{\mathrm{a}}\end{array}$ & $\begin{array}{l}133.2 \pm 15.8 \\
132.2 \pm 15.7\end{array}$ & $\begin{array}{l}0.218 \\
0.029\end{array}$ \\
\hline $\begin{array}{c}\text { D iastolic blc } \\
\text { baseline } \\
10 \text { years }\end{array}$ & $\begin{array}{l}(\mathrm{mmH} \mathrm{g}): \\
79.4 \pm 9.4 \\
74.1 \pm 8.6^{\mathrm{b}}\end{array}$ & $\begin{array}{l}78.4 \pm 8.4 \\
77.3 \pm 8.7\end{array}$ & $\begin{array}{l}0.332 \\
0.085\end{array}$ \\
\hline
\end{tabular}

$\mathrm{a} p=0.038 ;{ }^{b} p=0.023$ compared with baseline

Values are mean $\pm S D$

no longer closely tutored. The insulin dose after 10 years was $0.70 \pm 0.17 \mathrm{IU} / \mathrm{kg}$ in the ICT group and $0.67 \pm 0.18 \mathrm{lU} / \mathrm{kg}$ in the ST group ( $p=0.454)$.

Serious retinopathy and visual deterioration were more common in the ST group after 10 years (Table 2). A life table analysis of the risk of developing serious retinopathy (Fig. 1) showed a difference between the groups starting after 60 months. The mean photographic scores for red dots were $1.98 \pm 0.48$ in the right eye and $1.93 \pm 0.58$ in the left eye in the patients in the ICT group. The corresponding scores in the ST group were $2.05 \pm 0.48(p=0.087)$ and $2.15 \pm 0.49(p=0.048)$. Five patients in the ST group and one patient in the ICT group needed vitrectomy [2].

Nephropathy was more common in the ST group after 10 years (Table 2 ). Five of the ST patients who developed nephropathy had a normal albumin excretion at baseline. This was not the case in the ICT group. A s previously described, serious nephropathy, with reduced glomerular filtration, developed in six ST patients (always before the 7.5 years' study) but in none of the ICT patients [2]. A Itogether $30 \%$ of the patients in the ICT group and $33 \%$ of the patients

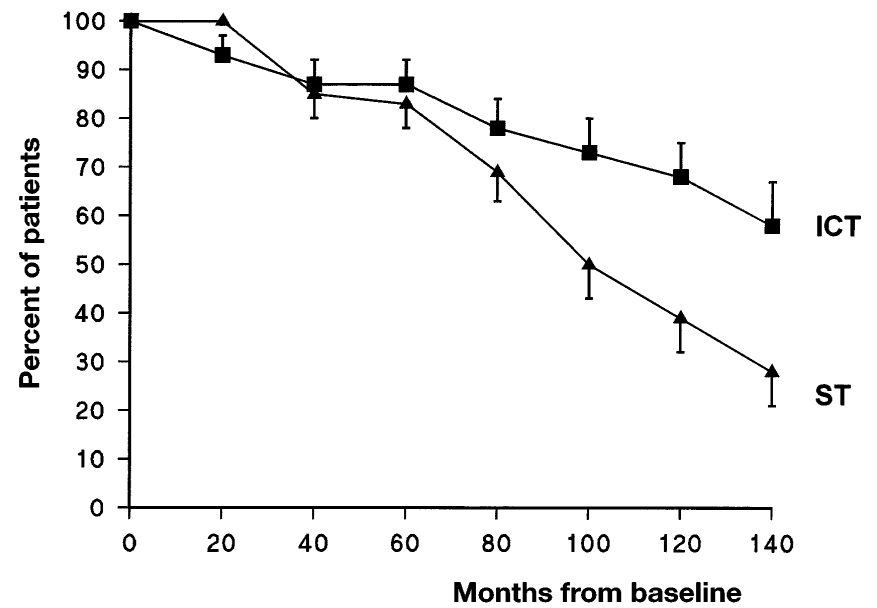

Fig. 1. Patients in the two treatment groups (\%) who did not develop serious retinopathy with the need for photocoagulation. Life table analysis of 102 patients who entered the study. $\mathrm{D}$ ata are mean $\pm \mathrm{SE} \mathrm{M}$

in the ST group were treated with anti-hypertensives, $21 \%$ of the patients in each group with angiotensin converting enzyme inhibitors. Systolic blood pressures were lower in the ICT group after 10 years, while there were no differences in mean glomerular filtration rates (Table 3 ).

The nerve conduction velocities in the legs were significantly lower in the ST group after 10 years (Table 4). M ore ST patients also had a reduced or absent ability to feel the needle during the pin prick test, and after 10 years, symptoms of neuropathy were more common in the ST group (Table 4). Neuropathy (symptoms and reduced nerve conduction) was present in $14 \%$ of the patients in the ICT group and $30 \%$ of the patients in the ST group $(p=0.065)$ after 10 years.

In the multivariate analyses overt nephropathy was related to smoking at entry to the study with an $O R$ of $4.64(1.20-17.94)(p=0.026)$, but smoking as an independent risk factor was eliminated when the mean $\mathrm{H} \mathrm{bA}_{1 \mathrm{c}}$ during 6-120 months was added. The patients who smoked at baseline had a $\mathrm{H} \mathrm{bA}_{1 \mathrm{c}}$ during the study of $8.0 \pm 1.0 \%$ while during the same period the patients who did not smoke had a $\mathrm{HbA}_{1 \mathrm{c}}$ of $7.6 \pm 0.9 \%$ $(p=0.026)$. Q uitting smoking was not independently related to serious retinopathy $(p=0.393)$, nephropathy $(p=0.620)$ or neuropathy $(p=0.567)$.

A mong the other potential risk factors only age was independently related to nephropathy (OR $=0.90$ (0.81-0.99), $p=0.0331$ ), and none was related to serious retinopathy or neuropathy. The odds ratios for $\mathrm{HbA}_{1 \mathrm{c}}$ during the study were 3.55 (1.667.56) $(p=0.001)$ for nephropathy, 2.70(1.55-4.69) $(p<0.001)$ for serious retinopathy and 3.13 (1.566.28) ( $p=0.001)$ for peripheral neuropathy.

O ver 10 years BMI increased from $22.5 \pm 2.0$ to $24.2 \pm 3.4 \mathrm{~kg} / \mathrm{m}^{2}$ in the ICT group $(p<0.001)$ and 
Table 4. Symptoms of neuropathy ( $\%$ of patients), pin prick sensitivity (number of patients with absent/decreased/normal) on the foot and first toe, and nerve conduction velocities of the peroneal, tibial and sural nerves

\begin{tabular}{|c|c|c|c|}
\hline & $\begin{array}{l}\text { Intensified } \\
\text { conventional } \\
\text { treatment }\end{array}$ & $\begin{array}{l}\text { Standard } \\
\text { treatment }\end{array}$ & $p$-values \\
\hline \multicolumn{4}{|c|}{ Symptoms of neuropathy: } \\
\hline baseline & 12 & 16 & 0.544 \\
\hline 10 years & $14^{\mathrm{a}}$ & $32^{b}$ & 0.041 \\
\hline \multicolumn{4}{|c|}{ Pin prick sensitivity (10 years) } \\
\hline foot & $1 / 4 / 38$ & $12 / 5 / 33$ & 0.010 \\
\hline toe & $2 / 3 / 38$ & $14 / 8 / 28$ & 0.002 \\
\hline \multicolumn{4}{|l|}{ NCV: } \\
\hline \multicolumn{4}{|l|}{ peroneal } \\
\hline base line & $42.9 \pm 4.4$ & $41.9 \pm 4.7$ & 0.322 \\
\hline 10 years & $41.3 \pm 3.8^{c}$ & $36.2 \pm 11.6^{d}$ & 0.007 \\
\hline \multicolumn{4}{|l|}{ tibial } \\
\hline base line & $41.3 \pm 5.4$ & $40.4 \pm 5.0$ & 0.435 \\
\hline 10 years & $41.1 \pm 4.2^{\mathrm{e}}$ & $35.1 \pm 11.8^{f}$ & 0.002 \\
\hline \multicolumn{4}{|l|}{ sural } \\
\hline base line & $44.2 \pm 8.6$ & $42.5 \pm 12.3$ & 0.482 \\
\hline 10 years & $39.7 \pm 12.0^{\mathrm{ag}}$ & $30.8 \pm 18.4^{h}$ & 0.008 \\
\hline
\end{tabular}

Compared with base line: ${ }^{a} p=0.767 ;{ }^{b} p=0.041 ;{ }^{c} p=0.01$; ${ }^{d} p<0.001 ;{ }^{e} p=0.855 ;{ }^{f} p=0.001 ;{ }^{g} p=0.004 ;{ }^{h} p<0.001$

NCV, N erve conduction velocity

Values for NCV are $\mathrm{m} / \mathrm{s}$, mean \pm SD

from $22.8 \pm 2.5$ to $23.9 \pm 2.9 \mathrm{~kg} / \mathrm{m}^{2}(p=0.001)$ in the ST group. The mean increase of BMI in the groups over 10 years was not significantly different $(p=0.165)$. During the first 5 years the increases were $1.3 \pm 1.9 \mathrm{~kg} / \mathrm{m}^{2}$ in the ICT group and $0.3 \pm$ $1.3 \mathrm{~kg} / \mathrm{m}^{2}$ in the ST group $(p=0.002)$.

D uring 10 years $86 \%$ of the ICT patients and $73 \%$ of the ST patients had one episode or more of serious hypoglycaemia ( $p=0.124)(58 \%$ and $43 \%$, respectively during the last 2.5 years, $p=0.140$ ). In the ICT group there was a mean of 1.06 episodes of serious hypoglycaemia per patient per year during the whole study, and in the ST group there were 0.47 episodes per patient per year (mean difference (95\% confidence interval) $0.59(0.20-0.98), p=0.003)$. During the last 2.5 years of the study there were 0.90 episodes per patient per year in the ICT group, and 0.66 episodes per patient per year in the ST group (difference $0.24(-0.29-0.78), p=0.359)$. $D$ uring the last 2.5 years of the study eight patients from each group needed emergency hospital care and intravenous glucose $(p=0.844)$. Five patients in the ICT group and two patients in the ST group received subcutaneous or intramuscular injections of glucagon outside of hospital $(p=0.192)$ during the same time period. A nalysing the whole study there were no serious accidents (car accidents or other situations with a person seriously hurt) associated with hypoglycaemia. The groups remained similar as to neuropsychological function (Table 5), and there were no significant correlations between the various tests of cognitive function and the total number of serious hypoglycaemic episodes. The
Table 5. Computerized tests used for the analysis of cognitive effects of serious hypoglycaemia

\begin{tabular}{|c|c|c|c|}
\hline & $\begin{array}{l}\text { Intensified } \\
\text { conventional } \\
\text { treatment }\end{array}$ & $\begin{array}{l}\text { Standard } \\
\text { treatment }\end{array}$ & p-values \\
\hline \multicolumn{4}{|l|}{$\begin{array}{l}\text { Visual reaction time with } \\
\text { auditory inhibitiona (ms) }\end{array}$} \\
\hline $\begin{array}{l}\text { right side } \\
\text { left side }\end{array}$ & $\begin{array}{l}361 \pm 87 \\
380 \pm 93\end{array}$ & $\begin{array}{l}341 \pm 74 \\
374 \pm 88\end{array}$ & $\begin{array}{l}0.254 \\
0.769\end{array}$ \\
\hline \multicolumn{4}{|l|}{$\begin{array}{l}\text { D igit span test (number } \\
\text { of digits remembered) }\end{array}$} \\
\hline $\begin{array}{l}\text { forwards } \\
\text { backwards }\end{array}$ & $\begin{array}{l}7.2 \pm 1.3 \\
7.0 \pm 1.4\end{array}$ & $\begin{array}{l}6.9 \pm 1.5 \\
6.6 \pm 1.5\end{array}$ & $\begin{array}{l}0.373 \\
0.167\end{array}$ \\
\hline $\begin{array}{l}\text { Trail making test } \\
\text { digits and letters }\end{array}$ & $2.1 \pm 0.6$ & $2.1 \pm 0.5$ & 0.786 \\
\hline \multicolumn{4}{|l|}{ M aze test ${ }^{b}$} \\
\hline $\begin{array}{l}\text { with target information } \\
\text { without target information }\end{array}$ & $\begin{array}{l}6.9 \pm 2.9 \\
7.3 \pm 3.8\end{array}$ & $\begin{array}{l}7.4 \pm 2.0 \\
7.4 \pm 4.2\end{array}$ & $\begin{array}{l}0.518 \\
0.844\end{array}$ \\
\hline
\end{tabular}

Table 6. Expected 10-year improvement of prognosis with regard to microvascular complications when patients are intensively instead of conventionally treated. Percent (95\% confidence interval) of patients expected to avoid the complication

\begin{tabular}{ll}
\hline Serious retinopathy & $29(10-48)^{\mathrm{a}}$ \\
Visual deterioration & $19(2-37)^{\mathrm{a}}$ \\
N ephropathy & $20(5-34)^{\mathrm{a}}$ \\
Symptoms of neuropathy & $19(2-35)$ \\
\hline
\end{tabular}

${ }^{a}$ A nalysis included two patients who died

interaction between neuropathy after 10 years and the total number of severe hypoglycaemic episodes during 10 years was significantly correlated with increased trail making time $(p=0.024)$. The same applied to the interaction between serious retinopathy after 10 years and the total number of hypoglycaemic episodes ( $p=0.002)$, but not for the interaction between nephropathy and hypoglycaemic episodes $(p=0.424)$. The trail making time was also borderline significantly correlated with higher $\mathrm{HbA}_{1 c}$ $(p=0.062)$. Digit span test results were better in patients with lower $\mathrm{HbA}_{1 \mathrm{c}}$ (forwards $\mathrm{p}=0.004$, backwards $p=0.004$ ). The maze test without target information was borderline significantly correlated with the interaction between neuropathy after 10 years and the total number of hypoglycaemic episodes $(p=0.099)$, and significantly so with the interaction between serious retinopathy and hypoglycaemia $(p=0.018)$, but not with the interaction between nephropathy and hypoglycaemia $(p=0.444)$.

Subjective well-being $(p=0.017)$ and perceived ability to control the diabetes $(p=0.001)$ were higher in the ICT group. Both well-being ( $r h o=0.352$, $p<0.001)$ and perceived ability to control the diabetes ( $r h o=0.328, p=0.011$ ) correlated negatively with mean $\mathrm{HbA}_{1 \mathrm{c}}$ during the study. 
The projected effects on complications of intensified treatment instead of standard treatment are shown in Table 6.

\section{Discussion}

The microvascular complications are reduced by intensified treatment as was already shown after 6.5 years [1] and 7.5 years [2]. It is important to establish that the results remain when intervention is brought to an end.

The results already reported after 7.5 years [2] were even more pronounced after 10 years, in spite of a slightly smaller difference between the treatment groups with regard to $\mathrm{HbA}_{1 \mathrm{c}}$. A s can be deduced from Figure 1 there is an apparent delay between the improvement of $\mathrm{HbA}_{1 \mathrm{c}}$ and the reduction of serious retinopathy, and the patients should be aware of this is order not to harbour unrealistic expectations.

It has al ready clarified that the blood glucose lowering programme should start before the worsening of mild retinopathy [16]. Serious retinopathy is treated with photocoagulation in order to prevent bleeding into the vitreous and reduced visual acuity caused by blood, macular oedema or impaired retinal blood flow. M ore patients from the ST group needed photocoagulation. A fter 10 years more patients from the ST group had deteriorated with regard to visual acuity, and the red dots score tended to be better in the patients from the ICT group.

Nephropathy developed in many ST patients, and some of them had a normal albumin excretion rate when the study started. The level of metabolic control achieved in the ICT group prevented this rapid deterioration.

Neuropathic symptoms were more common among the patients in the ST group after 10 years, while there were only subclinical differences after 7.5 years [2].

A fter 10 years blood pressure was lower in the ICT group, although each patient with increased blood pressure had received anti-hypertensive treatment. This difference was probably caused by the greater number of patients in the ST group who developed renal disease.

Patients in both groups also tended to smoke less after 10 years as compared with baseline. A s no special effort was made to make the patients stop smoking (although the patients were, of course, recommended not to smoke) this was a "spontaneous" process. While smokers had higher $\mathrm{HbA}_{1 c}$ than nonsmokers, there was no independent effect of smoking on nephropathy after 3 years [3], but smoking accelerated the progression of non-proliferative retinopathy during a 5-year period [17]. A fter 10 years we found no significant correlations between these serious complications and quitting smoking. Smokers had higher $\mathrm{HbA}_{1 c}$, while smoking itself did not lead to renal or other microvascular damage. These conclusions agree with those of another recent publication [18].

We also concluded that the treatment programme used in the ICT group increased the patients' subjective well being.

The frequency of severe hypoglycaemia increased when the patients underwent intensified treatment, but no serious incidents occurred; this frequency lessened during the last part of the study. Probably the patients knew better how to prevent hypoglycaemia, but other important factors must be analysed separately. A fter 10 years there were still no signs of cognitive deterioration in the patients in the ICT group. There were even signs of better performance as to short-term memory in patients with lower $\mathrm{H} \mathrm{bA}{ }_{1 c^{\circ}}$ Patients with neuropathy and/or serious retinopathy did less well on some of the tests when they had more episodes of severe hypoglycaemia. This agrees with our finding after 7.5 years [8] (based on $R$ yan et al. [19]) that severe hypoglycaemia seemed to be deleterious in patients with neuropathy. Profound hypoglycaemia with unconciousness is probably generally harmful to the brain, but the increase in frequency of severe hypoglycaemia experienced during intensified treatment did not lead to neuropsychological deterioration in the SDIS, nor in the DCCT [20].

The long-term complications are directly related to the elevated blood glucose level, and this is even more evident after a longer follow-up. No other important risk factors could be found.

I ntensified insulin treatment leads to reduced complications and improved well-being without undue risks in patients with poor metabolic control and nonproliferative retinopathy. O ne physician and one specialist nurse working together can intervene actively in and then educate at least 400 patients [21], the gains (Table 6) would be great in terms of patient satisfaction and societal economics. Treatment with photocoagulation, reduced visual acuity, treatment for endstage renal disease and amputations ultimately caused by neuropathy are difficult and expensive. We believe that the prophylactic effects of intensified insulin treatment are among the best that can be achieved by modern medicine. If this kind of treatment was to be generally implemented, the serious long-term complications of insulin-dependent diabetes could become uncommon [22].

\section{References}

1. The Diabetes Control and Complications Trial Research G roup (1993) The effect of intensive treatment of diabetes on the development and progression of long-term complications in insulin-dependent diabetes mellitus. N Engl J $M$ ed 329: 977-986 
2. R eichard P, N ilsson BY, R osenqvist U (1993) The effect of long-term intensified insulin treatment on the development of microvascular complications of diabetes mellitus. N Engl J Med 329: 304-309

3. R eichard P, R osenqvist U (1989) N ephropathy is delayed by intensified insulin treatment in patients with insulin-dependent diabetes mellitus and retinopathy. J Int M ed 226: 81-87

4. R eichard P, B ritz A, Cars I, N ilsson BY, Sobocinsky-O Isson B , R osenqvist U (1988) The Stockholm D iabetes Intervention Study (SD IS): 18 months' results. A cta M ed Scand 224: $115-22$

5. R eichard P, Toomingas B, R osenqvist U (1994) Changes in conceptions and attitudes during five years of intensified conventional insulin treatment: the Stockholm Diabetes Intervention Study (SDIS). The Diabetes Educator 20: 503-508

6. $R$ eichard $P, B$ erglund $B$, B ritz A , L evander S, R osenqvist $U$ (1991) H ypoglycemic episodes during intensified insulin treatment: increased frequency but no effect on cognitive function. J Int M ed 229: 9-16

7. R eichard P, B ritz A, R osenqvist U (1991) Intensified conventional insulin treatment and neuropsychological impairment. BM J 303: 1439-1442

8. R eichard P, Pihl M (1994) M ortality and treatment side-effects during long term intensified conventional treatment in the Stockholm D iabetes Intervention Study (SD IS). D iabetes 43: 313-17

9. R eichard P, Sule J, R osenqvist U (1991) Capillary loss and leakage after five years of intensified insulin treatment in patients with insulin dependent diabetes mellitus (ID D M ). O phthalmology 98: 1587-1593

10. E arly Treatment D iabetic R etinopathy Study (1980) M anual of operations. Public H ealth Service, B ethesda, M aryland

11. Ludin H-P (1980) Electromyography in practice. Georg Thieme Verlag Thieme-Stratton Inc., Stuttgart, N ew Y ork, pp 31-42
12. Chantler C, G arnett E S, Parsons V, Veall N (1969) G lomerular filtration rate measurement in man by the single injection method using ${ }^{51} \mathrm{Cr}$-E D TA . Clin Sci 37: 169-180

13. G ardner M J, A Itman D G (1989) Statistics with confidence. B M J, London, pp 29-30

14. B erkson J, G age R P (1950) Calculation of survival rates for cancer. Proc Staff M eet M ayo Clin 25: 270-286

15. B reslow NE, D ay NE (1980) Statistical methods in cancer research (vol 1). Lyon: IARC Scientific Publications N o. 32, pp 196-246

16. R eichard $P$ (1995) A re there any blood glucose thresholds for the deterioration of serious microvascular complications? J Diab Compl 9: 25-30

17. R eichard P ( 1992) R isk factors for progression of microvascular complications in the Stockholm Diabetes Intervention Study (SD IS). D iab R es Clin Pract 16: 151-156

18. Chaturvedi N, Stephenson J M, Fuller JH, The Eurodiab IDDM Complications Study Group (1995) The relationship between smoking and microvascular complications in the E urodiab IDDM Complications Study. D iabetes Care 18: $785-792$

19. R yan CM, Williams TM, O rchard TJ, Finegold D N (1992) Psychomotor slowing is associated with distal symmetrical polyneuropathy in adults with diabetes mellitus. Diabetes 41: 107-113

20. The Diabetes Control and Complications Trial Research Group (1996) Effects of intensified diabetes therapy on neuropsychological function in adults in the $D$ iabetes Control and Complications Trial. A nn I ntern M ed 124: 379-388

21. R eichard P (1994) A risk-benefit assessment of conventional versus intensive insulin therapy. D rug Safety 10: 196-202

22. Dahl-Jorgensen $K, B$ rinchman- $H$ ansen $O$, Bangstad $H \mathrm{~J}$, $\mathrm{H}$ anssen K F (1994) B lood glucose control and microvascular complications - what do we do now? D iabetologia 37: 1172-1177 